Article type: Research Article

\title{
Nitric oxide synthases from photosynthetic organisms improve growth and confer nitrosative stress tolerance in E. coli. Insights on the pterin cofactor
}

\author{
Authors \\ Natalia Correa-Aragunde*, Andrés Nejamkin, Fiorella Del Castello, Noelia Foresi and Lorenzo \\ Lamattina*
}

\section{Affiliations}

Instituto de Investigaciones Biológicas-CONICET, Universidad Nacional de Mar del Plata, CC1245, Mar del Plata, Argentina.

*Corresponding autor: Lorenzo Lamattina, Iolama@mdp.edu.ar; Natalia Correa-Aragunde, mncorrea@mdp.edu.ar

Natalia Correa-Aragunde (Orcid ID: 0000-0002-5234-2964)

Keywords: Escherichia coli, nitric oxide synthase, Ostreococcus tauri, Synechococcus PCC 7335

Data availability statement: The data that support the findings of this study are available from the corresponding author upon reasonable request. 


\section{Abstract}

Nitric oxide synthase (NOS) synthesizes NO from the substrate L-arginine (Arg). NOS with distinct biochemical properties were characterized from two photosynthetic microorganisms, the unicellular algae Ostreococcus tauri (OtNOS) and the cyanobacteria Synechococcus PCC 7335 (SyNOS). In this work we studied OtNOS and SyNOS recombinantly expressed in E. coli and analyzed bacterial growth and tolerance to nitrosative stress. Results show that the expression of OtNOS and SyNOS promotes bacterial growth and allows metabolizing Arg as $\mathrm{N}$ source. In accordance to a high NO producing activity, OtNOS expression induces the $h m p$ flavohemoglobin in E. coli, suggesting that this strain is sensing nitrosative stress. The addition of $1 \mathrm{mM}$ of the NO donor sodium nitroprusside (SNP) is toxic and generates a strong nitrosative stress. The expression of OtNOS or SyNOS reduced SNP toxicity restoring bacterial growth. Finally, using bioinformatic tools and ligand docking analyses, we propose tetrahydromonapterin ( $\mathrm{MH} 4)$, an endogenous pterin found in E. coli, as potential cofactor required for NOS catalytic activity. Our findings could be useful for the development of biotechnological applications using NOS expression to improve growth in bacteria.

\section{Key points}

- $\quad$ The NO synthase (NOS) from photosynthetic microorganisms were expressed in E. coli

- Expression of NOS increases bacterial growth and tolerance to nitrosative stress.

- Ligand docking analyses indicate tetrahydromonapterin (MH4) as potential NOS cofactor in $E$. coli.

\section{Introduction}

Nitric oxide synthase (NOS) enzymes catalyze the oxidation of L-arginine (Arg) to citrulline and nitric oxide (NO). Animal NOSs are homodimeric enzymes in which each monomer comprises an oxygenase domain and a reductase domain joined by a calmodulin binding motif. The oxygenase domain binds iron protoporphyrin IX (haem), the substrate Arg and the cofactor tetrahydrobiopterin (BH4) at the active site, while reductase domain contains the binding sites of the cofactors NADPH, FMN and FAD (Alderton et al. 2001). In mammals three isoforms were identified, the constitutive endothelial (eNOS) and neuronal NOS (nNOS) and a third inducible NOS (iNOS) found in macrophages (Alderton et al. 2001). The three of them present distinct biochemical properties (Stuehr et al. 2004).

Bacterial NOS, mostly found in Gram positive bacteria, have a single oxygenase domain receiving electrons from promiscuous cellular reductases (Gusarov et al. 2008). NOSs characterized from Bacillus subtilis, Deinococcus radiodurans and Sorangium cellulosum use tetrahydrofolate (THF) as 
bioRxiv preprint doi: https//doi.org/10.1101/2021.03.07.434255; this version posted March 8, 2021. The copyright holder for this preprint (which was not certified by peer review) is the author/funder, who has granted bioRxiv a license to display the preprint in perpetuity. It is made available under aCC-BY-ND 4.0 International license.

pterin cofactor since they lack the BH4 synthetic pathway (Pant et al. 2002; Adak et al. 2002b; Reece et al. 2009; Agapie et al. 2009). The biological functions of NOS in bacteria are diverse including tolerance to oxidative/nitrosative stress, secondary metabolite production, and cell growth recovery after oxidative stress (Kers et al. 2004; Gusarov and Nudler 2005; Patel et al. 2009; Zhao et al. 2020).

In the last decade, NOS from photosynthetic organisms were characterized. The NOS from the green alga Ostreococcus tauri (OtNOS) is structurally similar to the NOS described in animals (Foresi et al. 2010). Even though, some differences were found in OtNOS like the calmodulin binding domain and the lack of the autoinhibitory loop as occurs in iNOS. Biochemical in vitro studies showed that OtNOS oxygenase domain presents an ultrafast NO producing activity. Oxygen activation rate in OtNOS is greater, and NO dissociation was reported 10-80 times faster than in animal NOS (WeisslockerSchaetzel et al. 2017). OtNOS seems to be constitutively expressed in the alga, although higher expression was observed when the alga was exposed to high light irradiances, suggesting a role in photooxidative stress conditions (Foresi et al. 2010). Lately, the NOS from the cyanobacteria Synechococcus PCC 7335 (SyNOS) was identified (Correa-Aragunde et al., 2018). SyNOS architecture has several structural and biochemical features that make it rather different from other NOS described so far, and it challenges the current knowledge about NOSs physiological functions. SyNOS contains an additional globin domain in its $\mathrm{N}$-terminus, followed by the oxygenase and reductase domains (Correa-Aragunde et al. 2018; Picciano and Crane 2019). In vitro biochemical analyses indicate that SyNOS globin domain has a NO dioxygenase (NOD) activity, catalyzing the reduction of NO to nitrate $\left(\mathrm{NO}_{3}{ }^{-}\right.$) in the presence of $\mathrm{O}_{2}$ (Picciano and Crane 2019). SyNOS activity depends on extracellular $\mathrm{Ca}_{2}{ }^{+}$ (Picciano and Crane 2019), although neither calmodulin nor autoinhibitory loop was found in its structure (Correa-Aragunde et al. 2018). In in vitro experiments, it was also reported that SyNOS cannot use THF as cofactor and uses BH4.

Our previous results indicate that the expression of recombinant SyNOS confers E. coli the ability to grow at higher OD respect to bacteria expressing the empty vector (EV) and that SyNOS is able to metabolize arginine as $\mathrm{N}$ source (Correa-Aragunde et al. 2018). These results suggest that SyNOS may allow bacteria a gain of function to utilize N. However, it remains to confirm which pterin cofactor may SyNOS be using in E. coli. Here, we analyze and compare the effect of the expression of OtNOS and SyNOS in E. coli. We have studied the growth in different nutrient media, the expression of $h m p$ gene coding for the NO dioxygenase in E. coli and the tolerance to nitrosative stress. Results indicate that there are some differences between OtNOS and SyNOS regarding $E$. coli growth and nitrosative stress responses. In addition, we have performed in silico studies through structural modelling and ligand docking, for contributing to reveal novel insights about the putative pterin factors used by NOS in $E$. coli. 


\section{Materials and Methods}

\section{Bacterial strains and culture conditions}

The open reading frames of OtNOS and SyNOS were cloned in the bacterial expression vector PET24a with BamHI-XhOl and EcoRI-XhOl restriction sites respectively. A c-myc tag was added in the Cterminal of SyNOS. The clones were confirmed by DNA plasmid sequencing. Plasmids pET24 (empty vector, EV), pET24a-OtNOS (OtNOS) and pET24a-SyNOS (SyNOS) were used to transform Escherichia coli BL21 D3. The expression of recombinant NOS in E. coli cultures was induced by addition of $0.1 \mathrm{mM}$ of $\beta$ - D-1-thiogalactopyranoside (IPTG), $200 \mu \mathrm{M}$ of aminolevulinic acid (ALA, Sigma) and $1 \mathrm{mM}$ Arginine hydrochloride (Arg, Sigma) in Luria Broth (LB) medium containing $50 \mu \mathrm{g} / \mathrm{ml}$ of kanamycin (Kan, Sigma) and grown at $30 \circ \mathrm{C}$ in continuous agitation $(200 \mathrm{rpm})$ to allow oxygenation of the culture. The growth of cultures was followed by OD $600 \mathrm{~nm}$. The detection of recombinant proteins was analyzed by immunoblot using an anti-myc antibody (Sigma) for SyNOS and a specific OtNOS antibody generated by GenScript Company.

\section{Quantification on nitrate, nitrite and protein content}

Bacterial cultures containing Kan $50 \mu \mathrm{g} / \mathrm{ml}$ (OD aprox 0.25) were induced with $0.1 \mathrm{mM}$ IPTG, $200 \mu \mathrm{M}$ ALA and $1 \mathrm{mM} \mathrm{Arg}$. After $6 \mathrm{~h}$ induction, $3 \mathrm{ml}$ of cultures were collected by centrifugation at 5,000 rpm for $5 \mathrm{~min}$ and resuspended in $200 \mu \mathrm{l}$ of $1 \mathrm{X}$ phosphate saline buffer (PBS). Nitrite content was measured by the Griess reagent assay. Fifty $\mu \mathrm{l}$ of samples were incubated for 10 min with $50 \mu l$ of $1 \%(\mathrm{w} / \mathrm{v})$ sulfanilamide and then $50 \mu$ of $0.1 \%(w / v)$ NED was added. Nitrite content was determined by Abs $540 \mathrm{~nm}$ using a solution of sodium nitrite standard curve. Nitrate content was measured by the method described by Cataldo (1975). Briefly, $10 \mu$ of solution was incubated with $5 \%(w / v)$ salicylic acid in concentrated $\mathrm{H}_{2} \mathrm{SO}_{4}$ for 20 min. Then the solution was neutralized with $950 \mu \mathrm{l}$ of $2 \mathrm{~N} \mathrm{NaOH}$ and abs was measured at $401 \mathrm{~nm}$. Protein content in samples was measured by the Bradford method (Bradford 1976).

\section{RT-PCR analysis.}

For RT-PCR analysis, E. coli cultures were used after 2,4 and 6 h-induction with $0.1 \mathrm{mM}$ IPTG, $200 \mu \mathrm{M}$ ALA and $1 \mathrm{mM}$ Arg. Samples were collected by centrifugation at 5,000 rpm for $10 \mathrm{~min}$ and RNA was extracted with $1 \mathrm{ml}$ Trizol (Invitrogen) with glass beads. Then, $200 \mathrm{ul}$ of chloroform was added and 
centrifuged at 10,000 rpm for $15 \mathrm{~min}$. The aqueous solution was isolated, and the RNA precipitated by isopropanol addition and washed by ethanol $70 \%(\mathrm{v} / \mathrm{v})$.

The RNA was used for cDNA synthesis in a reaction containing $0.3 \mu$ of random primer, $1 \mu \mathrm{l}$ of $10 \mathrm{mM}$ dNTP, $2 \mu$ l of 0.1 M DTT and $200 \mathrm{U}$ of M-MLV reverse transcriptase (Invitrogen). The hcaT gene coding for the MSC transporter (accession number QJZ1029) was used as a reference gene since it is highly invariant in E. coli during recombinant protein production in different growth temperatures and induction conditions (Zhou et al. 2011). Primers used for hmp were: forward 5'TCCCTTTACTGGTGGAAACG-3` and reverse 5'-ACTGTTCCGGTTTGATCTGG-3', and for the hcat gene were: forward 5'-ATTGCTGCTCGCCAGGGTAG-3` and reverse 5'-CCAGCGCCATTACCCAGAAC-3`. Real time PCR was performed in StepOne equipment. LinRegPCR program was used for the analysis of qPCR data (Ruijter et al. 2009).

\section{Growth assay in minimal medium}

Bacterial cultures containing $50 \mu \mathrm{g} / \mathrm{ml}$ Kan (OD 600 approximately $0.25-0.3$ ) were induced with 0.1 mM IPTG, $200 \mu \mathrm{M}$ ALA and $1 \mathrm{mM}$ of Arg for $1.5 \mathrm{~h}$. Aliquots of cultures were diluted (1/100) to $10 \mathrm{ml}$ minimal media containing $5.44 \mathrm{~g} \mathrm{KH}_{2} \mathrm{PO}_{4}$ and $6 \mathrm{ml}$ salt solution $\left(10 \mathrm{~g} \mathrm{MgSO}_{4} .7 \mathrm{H}_{2} \mathrm{O}, 1.0 \mathrm{~g} \mathrm{MnCl}_{2} .4 \mathrm{H}_{2} \mathrm{O}\right.$, $0.4 \mathrm{~g} \mathrm{FeSO}_{4} .7 \mathrm{H}_{2} \mathrm{O}$ and $0.1 \mathrm{~g} \mathrm{CaCl}_{2} .2 \mathrm{H}_{2} \mathrm{O}$ per I) in $1 \mathrm{I}$ of distilled water. In these growth conditions, the induction of recombinant proteins was maintained by the addition of $0.1 \mathrm{mM} \mathrm{IPTG,} \mathrm{Kan} 50 \mu \mathrm{g} / \mathrm{ml}$ and $200 \mu \mathrm{M}$ ALA. Filter-sterilized glucose $(0.2 \%, \mathrm{w} / \mathrm{v})$ served as the carbon source with or without filtered-

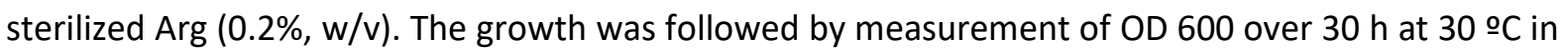
continuous agitation (200 rpm).

\section{Evaluation of resistance to nitrosative stress}

The evaluation of resistance to nitrosative stress was performed as described by Frey et al. (2002) with minor modifications. E. coli Cultures were induced with $0.1 \mathrm{mM}$ IPTG, $200 \mu \mathrm{M}$ ALA and $1 \mathrm{mM}$ of $\mathrm{Arg}$ for $1.5 \mathrm{~h}$ in LB medium at $30{ }^{\circ} \mathrm{C}$ and then was used to inoculate $3 \mathrm{ml}$ of fresh LB medium containing either $1 \mathrm{mM}$ nitroprusside sodium dihydrate (SNP; Fluka) to an initial OD 600 of approximately 0.2 . Cultures were further grown under identical conditions, and the OD 600 was measured at 30 ㄷ for 3 $\mathrm{h}$ in continuous agitation (200 rpm). Growth rates $(\mu)$ were calculated by applying linear regression analysis on the natural logarithm (In) of Abs 600 values versus time of culture as described by Frey et al. (2002). 


\section{Homology modelling and molecular docking}

NOS protein sequences and oxygenase domains were obtained from NCBI database. For tridimensional models building, @TOME v3 Platform (Pons \& Labesse - Nucleic Acids Research, Web Server Issue- 2009) was used to select the best crystalized template for each NOS of our study. Modeller V9.25 was used for the building of SyNOS model using Mus musculus iNOS (PDB code 1M8D) and OtNOS model using Bos Taurus eNOS (PDB code 1NSE) as template. Ten models were generated with a DOPE-based loop modeling protocol and the model with the lower DOPE was chosen for docking simulations (Šali and Blundell 1993).

Molecular docking was performed using AutoDock Vina (Trott, O. \& Olson. 2010) in Chimera software (Pettersen et al. 2004). First, docking assay was performed for the heam group since it is involved in pterin binding. The binding pocket of the heam group is highly conserved among NOSs and a similar haem bind position was found for OtNOS and SyNOS. Ligands, (6R)-2-amino-5,6,7,8-tetrahydro-6[(1S,2S)-1,2,3-trihydroxypropyl]pteridin4(3H)-one (MH4) and (6R)-2-amino-6-[(1R,2S)-1,2dihydroxypropyl]-5,6,7,8-tetrahydro-3H-pteridin-4-one (BH4) were built using Avogadro software (Hanwell et al. 2012) and the energy optimization was determined with PM6 method. Search space for pterins binding poses was set in a grid box of $12 \times 12 \times 12 \AA$ enclosing the arginine and tryptophan necessary for binding. For haem group the search space was set in a grid box of $14 \times 14 \times 14 \AA$ and the position was established taking as reference iNOS superposition. Exhaustiveness was set in 20. In all cases, poses that were not able to bind with the key residues reported were discarded. Visualizations and distance measures were done using Chimera tools.

\section{Statistical analysis}

Results are expressed as means \pm standard error. Data were analyzed by one-way analysis of variance (ANOVA) with post hoc Dunnett or Tukey method comparisons. We have developed linear mixed models with normal error structure using the Ime function from the nIme library in R software (version 3.1; R Foundation for Statistical Computing). For response variables that do not show a normal distribution, logarithmic transformations were applied, or a generalized linear model has been developed with Gamma error structure in R software. In all cases, transgene expression was set as a fixed effect and experiments were treated as a random effect. 


\section{Results}

\section{Growth of $E$. coli expressing recombinant OtNOS or SyNOS. Analysis of hmp expression}

We analyzed the effect of OtNOS and SyNOS expression in E. coli growth on LB medium. OtNOS and SyNOS expression in E. coli was induced by the addition of $0.1 \mathrm{mM}$ IPTG plus $200 \mathrm{uM}$ of the haem precursor aminolevulinic acid (ALA) to a growing culture (OD 0.25) in LB medium containing kanamycin. Bacteria growth was followed by measuring OD 600. Figure 1A shows that the expression of recombinant NOS enzymes allows a higher OD compared to bacteria expressing the empty vector (EV). The OD reached by bacteria expressing recombinant NOSs is $40 \%$ higher than EV. The higher biomass produced by the expression of recombinant NOS in bacteria is shown in Supplemental Fig. S1 and reflected in the protein content and nitrate of cells (Supplemental Table S1), especially in the strain expressing SyNOS. The expression of OtNOS and SyNOS (119 kDa and 167 kDa respectively) was detected by immunoblot after $2 \mathrm{~h}$ of IPTG induction (Fig. 1B). Supplemental Fig. S2 shows that the effect of NOS expression on bacterial growth is completely abolished when bacteria are grown without IPTG addition. The increased growth rate of $E$. coli expressing SyNOS was reported previously (CorreaAragunde et al. 2018), but was not tested for another NOS from photosynthetic microorganism like OtNOS.

The bacterial NO dioxygenase gene $(h m p)$ is considered a nitrosative stress sensor (Forrester and Foster 2012). HMP is capable of the conversion of $\mathrm{NO}$ to $\mathrm{NO}_{3}{ }^{-}$in an $\mathrm{O}_{2}$-dependent manner. The expression of $h m p$ was analyzed in E. coli after induction of OtNOS and SyNOS by quantitative PCR. The induction of $h m p$ was detected after $4 \mathrm{~h}$ of OtNOS induction (Fig. 2). The OtNOS-dependent $h m p$ induction reaches up to 6-fold respect to EV expressing bacteria. This result was not surprising since OtNOS appears to be an ultra-fast NO-releasing enzyme (Weisslocker-Schaetzel et al., 2017). SyNOS expression did not produce induction of the $h m p$ gene at the same analyzed times (Fig. 2), suggesting that the NOD activity of the SyNOS-globin domain may be catalyzing the oxidation of $\mathrm{NO}$ to $\mathrm{NO}_{3}{ }^{-}$, thus these cells are not sensing nitrosative stress.

Effect of SyNOS and OtNOS expression on the $E$. coli growing in minimal medium with arginine as $\mathbf{N}$ source

Since NOS are arginine-degrading enzymes, we tested whether OtNOS expression in E. coli contributes to growth with arginine as a sole $\mathrm{N}$ source, as was previously evaluated with SyNOS (Correa-Aragunde et al., 2018). The hypothesis that we handle is that OtNOS may be able to produce NO and then $h m p$ induction (Fig. 2) could catalyze the conversion of $\mathrm{NO}$ to $\mathrm{NO}_{3}{ }^{-}$. NOS expression was induced with IPTG 
addition for $1.5 \mathrm{~h}$ in LB medium and then an aliquot ( $100 \mu \mathrm{l})$ was transferred to $10 \mathrm{ml}$ minimal medium containing $0.2 \%(\mathrm{w} / \mathrm{v})$ glucose and $0.2 \%(\mathrm{w} / \mathrm{v})$ arginine, maintaining the induction with $0.1 \mathrm{mM}$ IPTG. Bacterial growth was followed by measuring OD 600. Figure A shows that OtNOS expressing bacteria, as well as SyNOS expressing bacteria, can grow with arginine as $\mathrm{N}$ source. At the times evaluated, it was negligible the growth of IPTG-induced EV bacteria, in contrast to another study (Picciano and Crane 2019). The maximum OD reached by OtNOS expressing bacteria is lower than SyNOS expressing ones, suggesting that OtNOS-HMP combined activity could be less effective than SyNOS containing the intrinsic NOD activity (Fig. 3). We also performed an experiment with a prior wash of cell pellets before the transfer to the minimal medium, as performed in Picciano and Crane (2019) (Supplemental Fig. S4). Some differences were observed such as delayed growth and less final OD reached by the strains, but again SyNOS-expressing strains generated the higher OD (Supplemental Fig. S4).

\section{The expression of recombinant OtNOS and SyNOS protects $E$. coli from nitrosative stress}

Furthermore, we analyzed whether the expression of NOS in E. coli could protect bacteria from nitrosative stress. NOS expression was induced with IPTG addition for $1.5 \mathrm{~h}$ in LB medium and then was diluted to OD 0.2 maintaining IPTG induction and Kan selection. Nitrosative stress was induced by the addition of $1 \mathrm{mM}$ sodium nitroprussiate (SNP). Growth was followed by OD 600 over $3 \mathrm{~h}$ with agitation to allow the adequate expression of the recombinant NOS proteins over the whole experiment. Figure 4 shows that NOS expressing culture achieved significantly higher $\mu S N P$ / $\mu$ nostress ratios than the EV strain. The growth rates of E. coli cultures expressing either OtNOS or SyNOS were barely affected by nitrosative stress compared to EV cells, indicating that NOS expression aids cultures to counter SNP toxicity. OtNOS E. coli strain showed $\mu$ SNP/ $\mu$ no-stress ratio of approximately 0.8 , far more effective than SyNOS expression ( $\mu \mathrm{SNP} / \mu$ no stress ratio 0.6 ). These results suggest that OtNOS expression may induce a priming effect since its expression induces the $h m p$ gene (Fig. 2). On the other hand, partial SyNOS protection could come from SyNOS dioxygenase activity of the globin domain.

\section{Analysis of putative pterins that could be operating as NOS cofactors in E. coli}

Given the controversy about the type of pterin cofactor that NOS expressed in E. coli is using, and considering that: (i) $\mathrm{BH} 4$ is absent in this bacterium, which has not endogenous NOS and (ii) in vitro activity indicates that SyNOS does not utilize THF (Picciano and Crane 2019), we conducted an in silico study to shed some light on the matter. Both cofactors $\mathrm{BH} 4$ and THF share the pterin ring necessary 
for the electron donor process though its $\mathrm{R}$ side chain is different (Fig. 5A). However, some studies point out that L-tetrahydromonapterin (MH4), is one of the major pterins synthesized by $E$. coli (Ikemoto et al. 2002; Pribat et al. 2010). MH4 has a trihydroxypropyl as R side chain instead of the dihydroxypropyl chain present in BH4 (Fig. 5A). Taking into account that the $\mathrm{R}$ side chain of BH4 is not apparently involved in the electron donor process during NOS activity (Bird et al. 2002; Crane et al. 2010; Weisslocker-Schaetzel et al. 2017), this sole difference between both cofactors BH4 and MH4 allow us to postulate $\mathrm{MH} 4$ as the cofactor responsible for NOS activity in E. coli. This hypothesis is, in addition, supported by the fact that a structural isomer of $\mathrm{MH} 4$, the tetrahydroneopterin $(\mathrm{NH} 4)$, is able to replace BH4 in mammal NOS catalysis under in vitro conditions (Presta et al. 1998; Gorren et al. 2001). Here, we generated tridimensional models for SyNOS and OtNOS using crystalized mammal NOS as template and utilized them in docking assay to assess $\mathrm{BH} 4$ and $\mathrm{MH} 4$ binding positions (Fig. 5B, $C$ and $D)$. Results indicate that almost all residues from the pterin pocket of mammal NOS are conserved in SyNOS and OtNOS with a remarkably similar structural alignment (RMSD 0.219 and $0.481 \AA ̊$ respectively). Only minor changes were detected in the position of key residues for the pterin binding between iNOS and SyNOS, that were also reported for OtNOS (Weisslocker-Schaetzel et al. 2017), suggesting that these differences may not affect NOS activity. 1456 in iNOS is replaced by K391 in OtNOS (Fig. 5C) and G804 in SyNOS (Fig. 5D). Moreover, superimposed 3D structures show that the R723 guanidinium in SyNOS is displaced 1.8̊̊ from R375 of iNOS (Supplemental Fig. S6).

In agreement with the structural changes in pterin binding residues described, molecular docking analysis revealed distinct positions for $\mathrm{BH} 4$ binding in OtNOS and SyNOS when it was compared with the crystalized position in iNOS (PDB 1M8D). Figures $5 \mathrm{C}$ and $\mathrm{D}$ show the position of $\mathrm{BH} 4$ in OtNOS and SyNOS that allow the binding ( $\mathrm{H}$-bonds and $\pi$-stacking) with the key residues necessary for cofactor stabilization and electron donation. Likewise, the possible binding position for $\mathrm{MH} 4$ cofactor performed by docking assay is like BH4 localization irrespective of the NOS analyzed (Fig. 5B, C and D). Delta free energy of $\mathrm{BH} 4$ and $\mathrm{MH} 4$ binding show similar negative values in all the NOS analyzed, though SyNOS showed a little less affinity due to the absence of residue interaction with pterin R chain (Fig. $5 \mathrm{E})$. All at once, these evidences suggest that $\mathrm{MH} 4$ could bind in a similar position and affinity as $\mathrm{BH} 4$ and sustain NOS catalytic activity in $E$. coli.

\section{Discussion}

In this work, we present evidence that heterologous expression of NOS proteins from photosynthetic microorganisms generates active enzymes in E. coli. The recombinant NOS expression promotes the 
bioRxiv preprint doi: https//doi.org/10.1101/2021.03.07.434255; this version posted March 8,2021 . The copvriaht holder for this preprint (which was not certified by peer review) is the author/funder, who has granted bioRxiv a license to display the preprint in perpetuity. It is made available under aCC-BY-ND 4.0 International license.

growth in complete culture media and contributes to counteract nitrosative stress in E. coli. The involvement of bacterial NOS in cell proliferation and growth recovery after oxidative stress was previously reported (Gusarov and Nudler 2005; Shatalin et al. 2008; Gusarov et al. 2009). In D. radiodurans, UV irradiation induces upregulation of NOS gene, and NOS-derived NO upregulates obgE, a transcription factor involved in bacterial growth proliferation and stress response. Authors indicate that NO acts as a molecular signal for the regulation of growth in D. radiodurans (Patel et al. 2009). Likewise, $\triangle N O S$ strains of $B$. subtilis show a delayed growth response compared to the wt. It seems that NO is required for maintaining normal cell growth rate in B. subtilis, mainly at the entering of the stationary phase (Gusarov and Nudler 2005).

It is well known that IPTG addition has a negative impact on bacterial cell growth and compromises the biochemistry and physiology of the strain used for recombinant expression (Kosinski et al. 1992; Malakar and Venkatesh 2012; Lecina et al. 2013; Dvorak et al. 2015). IPTG achieves both, high levels of foreign gene expression and a high cell density and, at the same time, it is difficult for the host bacteria because of: (i) the accumulation of toxic waste products (i.e. acetic acid), (ii) the consumption of precursors to allow the synthesis of foreign proteins and selection markers and (iii) the replication of plasmid vectors. In this context, IPTG addition affects the final OD reached by the EV strain while OtNOS and SyNOS expression can partially overcome this restriction when grown in complete LB medium (Fig. 1 and Supplemental Fig. S1). This result suggests that NOS expression could be applied as a tool to keep the potential of bacterial growth during the production of recombinant proteins of commercial interest.

Picciano and Crane (2019) inquired about the nature of the pterin cofactor needed for SyNOS activity in E. coli since this bacterium does not have sepiapterin reductase involved in the synthesis of $\mathrm{BH} 4$ and, additionally, SyNOS is not active with THF at least in in vitro assays. THF is a molecule that contains a bulkier R side chain (glutamyl p-amino benzoic acid, pABA) than BH4 and MH4 (Fig. 5A), needing more physical space in the NOS pterin pocket. Also, this PABA side chain has to be surrounded by residues that provide electrostatic stability to preserve its binding for electron donation. Crane et al. (2010) established that mammals NOS are not structurally able to bind THF. Although this cofactor seems to be functional for OtNOS (Foresi et al. 2015), Weisslocker-Schaetzel et al. (2017) have described the structural disadvantages that THF could have for its binding. In contrast, bacterial NOSs (i.e. B. subtilis, D. radiodurans) have a more open pterin pocket, allowing THF to bind and act as a redox cofactor (Adak et al. 2002b; Adak et al. 2002a). Nevertheless, there still remains some doubts about the native NOS cofactor in bacteria, since THF fails to activate NOS from Staphylococcus aureus (Bird et al. 2002). In the case of SyNOS, where its dimerization structure is unknown, and the whole 
bioRxiv preprint doi: https//doi.org/10.1101/2021.03.07.434255; this version posted March 8, 2021. The copyright holder for this preprint (which was not certified by peer review) is the author/funder, who has granted bioRxiv a license to display the preprint in perpetuity. It is made available under aCC-BY-ND 4.0 International license.

enzyme folding with its globin domain has not been established, further analysis is needed to determine the specific disability for THF binding.

Curiously, it was demonstrated that the oxygenase domain of rat nNOS is functionally active in E. coli, although this NOS also exclusively uses BH4 instead of THF (Gusarov et al. 2008). Authors observed a higher $\mathrm{NO}_{2}{ }^{-}$and $\mathrm{NO}_{3}{ }^{-}$production in $E$. coli cells expressing a rat $\mathrm{nNOS}$ or $B$. subtilis NOS when compared to BL21 control bacteria. However, the authors did not refer to which pterin cofactor nNOS may be using (Gusarov et al. 2008). Gorren et al. (2001) analyzed which of many pterins are able to function as human NOS cofactors due to their redox properties. Interestingly, they have shown that $\mathrm{NH}_{4}$, a structural isomer of $\mathrm{MH} 4$, could support NOS activity. E. coli synthesizes considerable amounts of $\mathrm{MH} 4$ by the action of two characterized enzymes called FolX (neopterin epimerase) and FolM (monapterin reductase) (Pribat et al. 2010). Also oxidized monapterin was found to be excreted in the bacterial culture medium, however the role of the excreted pterin by bacteria is still unknown (Wachter et al. 1980). In Pseudomonas aeruginosa, MH4 seems to act as the cofactor of the enzyme phenylalanine hydroxylase (Pribat et al. 2010), a BH4-dependent enzyme in animals. In agreement with this, the analysis of the recombinant expression of a mouse BH4-dependent tyrosine hydroxylase in E. coli, only showed activity in wt strains, whereas in mutant strains ( $f \circ I X$ and $f o l M$ ) lacking $\mathrm{MH} 4$ synthesis route, no activity was detected (Satoh et al. 2012). These results strongly indicate that $\mathrm{MH} 4$ can replace $\mathrm{BH} 4$ in a human BH4-dependent enzyme.

When the genome of Synechococcus PCC was analyzed to find a gene coding for a sepiapterin reductase (SPR), one sequence revealed a $30 \%$ similarity, next to the gene encoding GTP cyclohydrolase I (GTPCH I). This sequence encodes for a short-chain dehydrogenase (SDR) domain and authors speculated that this strain may synthesize BH4 (Picciano and Crane 2019). However, the SDR family is a large family of oxidoreductases (Kavanagh et al. 2008) and this sequence lacks the specific motif of the pteridine reductases (an Arg in place of the Gly at position 6 in the TGX ${ }_{3} R X G$ motif) (Labine et al. 2020). Thereby, it remains to be elucidated whether Synechococcus PCC 7335 can synthesize BH4. Here we show that the expression of both SyNOS and OtNOS slightly increases the E. coli growth in minimal medium, and this contrast to the result showed by Picciano and Crane (2019). We postulate that the addition of IPTG to maintain NOS expression in our experiments described in this article and those previously reported (Correa-Aragunde et al, 2018), is the main difference compared to experiments performed in Crane's lab., and that it could be responsible for the differing results.

In summary, our results show that recently described NOSs from photosynthetic organisms increase the growth and confers oxidative stress tolerance in E. coli. These properties might be interesting to apply in biotechnological uses, such as production of polymers, secondary metabolites and antibiotics 
in E. coli. Besides, the analysis allows us to firmly postulate $\mathrm{MH} 4$ as a pterin cofactor in $E$. coli to sustain NOS activity. These results open new windows to discuss about the versatility of pterin cofactors working in NOSs.

AUTHOR CONTRIBUTIONS: NC-A, FDC and N.F designed and performed all experiments. A.N conducted statistical and ligand docking analysis. NC-A and AN wrote the manuscript. NC-A and LL analyzed the data and initiated and supervised the project.

\section{FUNDING}

This research was supported by the Agencia Nacional de Promoción Científica y Tecnológica (ANPCyT: PICTs 2927/2015 to LL and PICT 2524/2018 to NC-A.), the Consejo Nacional de Investigaciones Científicas y Técnicas (CONICET, PIP 0646/2015 to NC-A) and institutional grants from the Universidad Nacional de Mar del Plata (UNMdP), Argentina.

\section{ACKNOWLEDGMENTS}

We acknowledge Mar del Plata University and the Consejo Nacional de Investigaciones Científicas y Técnicas (CONICET). FC and AN are PhD fellows and NF, LL, and NC-A are members of the research staff from CONICET, Argentina.

\section{CONFLICT OF INTEREST}

The authors declare that they have no conflict of interest.

\section{ETHICAL STATEMENT}

This article does not contain any studies with human participants or animals performed by any of the authors.

\section{REFERENCES}


Adak S, Aulak KS, Stuehr DJ (2002a) Direct evidence for nitric oxide production by a nitric-oxide synthase-like protein from Bacillus subtilis. J Biol Chem 277:16167-71 . https://doi.org/10.1074/jbc.M201136200

Adak S, Bilwes AM, Panda K, Hosfield D, Aulak KS, McDonald JF, Tainer J a, Getzoff ED, Crane BR, Stuehr DJ (2002b) Cloning, expression, and characterization of a nitric oxide synthase protein from Deinococcus radiodurans. Proc Natl Acad Sci U S A 99:107-112. https://doi.org/10.1073/pnas.012470099

Agapie T, Suseno S, Woodward JJ, Stoll S, Britt RD, Marletta MA (2009) NO formation by a catalytically self-sufficient bacterial nitric oxide synthase from Sorangium cellulosum. Proc Natl Acad Sci U S A 106:16221-16226 . https://doi.org/10.1073/pnas.0908443106

Alderton WK, Cooper CE, Knowles RG (2001) Nitric oxide synthases: structure, function and inhibition. Biochem J 357:593-615 . https://doi.org/10.1042/bj3570593

Bird LE, Ren J, Zhang J, Foxwell N, Hawkins AR, Charles IG, Stammers DK (2002) Crystal structure of SANOS, a bacterial nitric oxide synthase oxygenase protein from Staphylococcus aureus. Structure 10:1687-1696 . https://doi.org/10.1016/S0969-2126(02)00911-5

Bradford MM (1976) A rapid and sensitive method for the quantitation of microgram quantities of protein utilizing the principle of protein-dye binding. Anal Biochem 72:248-54

Cataldo DA, Haroon MH, Schrader LE, Youngs VL, Maroon M, Schrader LE, Youngs VL (1975) Rapid colorimetric determination of nitrate in plant tissue by nitration of salicylic acid. Commun Soil Sci Plant Anal 6:71-80 . https://doi.org/10.1080/00103627509366547

Correa-Aragunde N, Foresi N, Del Castello F, Lamattina L (2018) A singular nitric oxide synthase with a globin domain found in Synechococcus PCC 7335 mobilizes N from arginine to nitrate. Sci Rep 8:1-11 . https://doi.org/10.1038/s41598-018-30889-6

Crane BR, Sudhamsu J, Patel BA (2010) Bacterial nitric oxide synthases. Annu Rev Biochem 79:44570 . https://doi.org/10.1146/annurev-biochem-062608-103436

Dvorak P, Chrast L, Nikel PI, Fedr R, Soucek K, Sedlackova M, Chaloupkova R, Lorenzo V, Prokop Z, Damborsky J (2015) Exacerbation of substrate toxicity by IPTG in Escherichia coli BL21(DE3) carrying a synthetic metabolic pathway. Microb Cell Fact 14:1-15 . https://doi.org/10.1186/s12934-015-0393-3

Foresi N, Correa-Aragunde N, Parisi G, Calo G, Salerno G, Lamattina L (2010) Characterization of a nitric oxide synthase from the plant kingdom: NO generation from the green alga Ostreococcus 
tauri is light irradiance and growth phase dependent. Plant Cell 22:3816-3830 .

https://doi.org/10.1105/tpc.109.073510

Foresi N, Mayta ML, Lodeyro AF, Scuffi D, Correa-Aragunde N, García-Mata C, Casalongué C, Carrillo $N$, Lamattina L (2015) Expression of the tetrahydrofolate-dependent nitric oxide synthase from the green alga Ostreococcus tauri increases tolerance to abiotic stresses and influences stomatal development in Arabidopsis. Plant J 82:806-821 . https://doi.org/10.1111/tpj.12852

Forrester MT, Foster MW (2012) Protection from nitrosative stress: A central role for microbial flavohemoglobin. Free Radic Biol Med 52:1620-1633 . https://doi.org/10.1016/j.freeradbiomed.2012.01.028

Frey AD, Farrés J, Bollinger CJT, Kallio PT, Frey AD, Farre J, Bollinger CJT, Kallio PT (2002) Bacterial Hemoglobins and Flavohemoglobins for Alleviation of Nitrosative Stress in Escherichia coli Bacterial Hemoglobins and Flavohemoglobins for Alleviation of Nitrosative Stress in Escherichia coli. https://doi.org/10.1128/AEM.68.10.4835

Gorren ACF, Kungl AJ, Schmidt K, Werner ER, Mayer B (2001) Electrochemistry of pterin cofactors and inhibitors of nitric oxide synthase. Nitric Oxide - Biol Chem 5:176-186 . https://doi.org/10.1006/niox.2001.0332

Gusarov I, Nudler E (2005) NO-mediated cytoprotection: Instant adaptation to oxidative stress in bacteria. Proc Natl Acad Sci 102:13855-13860 . https://doi.org/10.1073/pnas.0504307102

Gusarov I, Shatalin K, Starodubtseva M, Nudler E (2009) Endogenous Nitric Oxide Protects Bacteria Against a Wide Spectrum of Antibiotics. Science (80- ) 325:1380-1384 . https://doi.org/10.1126/science.1175439

Gusarov I, Starodubtseva M, Wang Z-Q, McQuade L, Lippard SJ, Stuehr DJ, Nudler E (2008) Bacterial Nitric-oxide Synthases Operate without a Dedicated Redox Partner. J Biol Chem 283:1314013147 . https://doi.org/10.1074/jbc.M710178200

Hanwell MD, Curtis DE, Lonie DC, Vandermeersch T, Zurek E, Hutchison GR (2012) Avogadro: an advanced semantic chemical editor, visualization, and analysis platform. J Cheminform 4:17 . https://doi.org/10.1186/1758-2946-4-17

Ikemoto K, Sugimoto T, Murata S, Tazawa M, Nomura T, Ichinose H, Nagatsu T (2002) (6R)-5,6,7,8tetrahydro-L-monapterin from Escherichia coli, a novel natural unconjugated tetrahydropterin. Biol Chem 383:325-330 . https://doi.org/10.1515/BC.2002.035

Kavanagh KL, Jörnvall H, Persson B, Oppermann U (2008) Medium- and short-chain 
dehydrogenase/reductase gene and protein families: The SDR superfamily: Functional and structural diversity within a family of metabolic and regulatory enzymes. Cell Mol Life Sci 65:3895-3906 . https://doi.org/10.1007/s00018-008-8588-y

Kers JA, Wach MJ, Krasnoff SB, Widom J (2004) Nitration of a peptide phytotoxin by bacterial nitric oxide synthase. Nature 429:79-82 . https://doi.org/10.1038/nature02451.1.

Kosinski MJ, Rinas U, Bailey JE (1992) Isopropyl- $\beta$-d-thiogalactopyranoside influences the metabolism of Escherichia coli. Appl Microbiol Biotechnol 36:782-784 . https://doi.org/10.1007/BF00172194

Labine M, DePledge L, Feirer N, Greenwich J, Fuqua C, Allen KD (2020) Enzymatic and mutational analysis of the prua pteridine reductase required for pterin-dependent control of biofilm formation in Agrobacterium tumefaciens. J Bacteriol 202: . https://doi.org/10.1128/JB.0009820

Lecina M, Sarró E, Casablancas A, Gòdia F, Cairó JJ (2013) IPTG limitation avoids metabolic burden and acetic acid accumulation in induced fed-batch cultures of Escherichia coli M15 under glucose limiting conditions. Biochem Eng J 70:78-83 . https://doi.org/10.1016/j.bej.2012.10.006

Malakar P, Venkatesh K V. (2012) Effect of substrate and IPTG concentrations on the burden to growth of Escherichia coli on glycerol due to the expression of Lac proteins. Appl Microbiol Biotechnol 93:2543-2549 . https://doi.org/10.1007/s00253-011-3642-3

Pant K, Bilwes AM, Adak S, Stuehr DJ, Crane BR (2002) Structure of a nitric oxide synthase heme protein from Bacillus subtilis. Biochemistry 41:11071-11079 . https://doi.org/10.1021/bi0263715

Patel B a, Moreau M, Widom J, Chen H, Yin L, Hua Y, Crane BR (2009) Endogenous nitric oxide regulates the recovery of the radiation-resistant bacterium Deinococcus radiodurans from exposure to UV light. Proc Natl Acad Sci U S A 106:18183-8 . https://doi.org/10.1073/pnas.0907262106

Pettersen EF, Goddard TD, Huang CC, Couch GS, Greenblatt DM, Meng EC, Ferrin TE (2004) UCSF Chimera - A visualization system for exploratory research and analysis. J Comput Chem 25:1605-1612 . https://doi.org/10.1002/jcc.20084

Picciano AL, Crane BR (2019) A nitric oxide synthase-like protein from Synechococcus produces $\mathrm{NO} / \mathrm{NO}_{3}{ }^{-}$from $\mathrm{l}$-arginine and NAPDH in a tetrahydrobiopterin- and $\mathrm{Ca}^{2+}$-dependent manner. J 
Biol Chem 294:10708-10719 . https://doi.org/10.1074/jbc.RA119.008399

Presta A, Siddhanta U, Wu C, Sennequier N, Huang L, Abu-Soud HM, Erzurum S, Stuehr DJ (1998) Comparative functioning of dihydro- and tetrahydropterins in supporting electron transfer, catalysis, and subunit dimerization in inducible nitric oxide synthase. Biochemistry 37:298-310 . https://doi.org/10.1021/bi971944c

Pribat A, Blaby IK, Lara-Núñez A, Gregory JF, De Crécy-Lagard V, Hanson AD (2010) FolX and FolM are essential for tetrahydromonapterin synthesis in Escherichia coli and Pseudomonas aeruginosa. J Bacteriol 192:475-482 . https://doi.org/10.1128/JB.01198-09

Reece SY, Woodward JJ, Marletta MA (2009) Synthesis of nitric oxide by the NOS-like protein from Deinococcus radiodurans : A direct role for tetrahydrofolate. Biochemistry 48:5483-5491 . https://doi.org/10.1021/bi900385g

Ruijter JM, Van der Velden S, Ilgun A (2009) LinReg PCR (11.0). Anal Quant

Šali A, Blundell TL (1993) Comparative Protein Modelling by Satisfaction of Spatial Restraints. J Mol Biol 234:779-815 . https://doi.org/https://doi.org/10.1006/jmbi.1993.1626

Satoh Y, Tajima K, Munekata M, Keasling JD, Lee TS (2012) Engineering of I-tyrosine oxidation in Escherichia coli and microbial production of hydroxytyrosol. Metab Eng 14:603-610 . https://doi.org/10.1016/j.ymben.2012.08.002

Shatalin K, Gusarov I, Avetissova E, Shatalina Y, McQuade LE, Lippard SJ, Nudler E (2008) Bacillus anthracis-derived nitric oxide is essential for pathogen virulence and survival in macrophages. Proc Natl Acad Sci U S A 105:1009-1013 . https://doi.org/10.1073/pnas.0710950105

Stuehr DJ, Santolini J, Wang Z-Q, Wei C-C, Adak S (2004) Update on mechanism and catalytic regulation in the NO synthases. J Biol Chem 279:36167-70 . https://doi.org/10.1074/jbc.R400017200

Wachter H, Hausen A, Reider E, Schweiger M (1980) Pteridine excretion from cells as indicator of cell proliferation. Naturwissenschaften 67:610-611 . https://doi.org/10.1007/BF00396550

Weisslocker-Schaetzel M, André F, Touazi N, Foresi N, Lembrouk M, Dorlet P, Frelet-Barrand A, Lamattina L, Santolini J (2017) The NOS-like protein from the microalgae Ostreococcus tauri is a genuine and ultrafast NO-producing enzyme. Plant Sci 265:100-111 . https://doi.org/10.1016/j.plantsci.2017.09.019

Zhao G, Guo YY, Yao S, Shi X, Lv L, Du YL (2020) Nitric oxide as a source for bacterial triazole 
bioRxiv preprint doi: https://doi.org/10.1101/2021.03.07.434255; this version posted March 8, 2021. The copyright holder for this preprint (which was not certified by peer review) is the author/funder, who has granted bioRxiv a license to display the preprint in perpetuity. It is made available under aCC-BY-ND 4.0 International license.

biosynthesis. Nat Commun 11:1-10 . https://doi.org/10.1038/s41467-020-15420-8

Zhou K, Zhou L, Lim Q, Zou R, Stephanopoulos G, Too HP (2011) Novel reference genes for quantifying transcriptional responses of Escherichia coli to protein overexpression by quantitative PCR. BMC Mol Biol 12:18 . https://doi.org/10.1186/1471-2199-12-18 
a

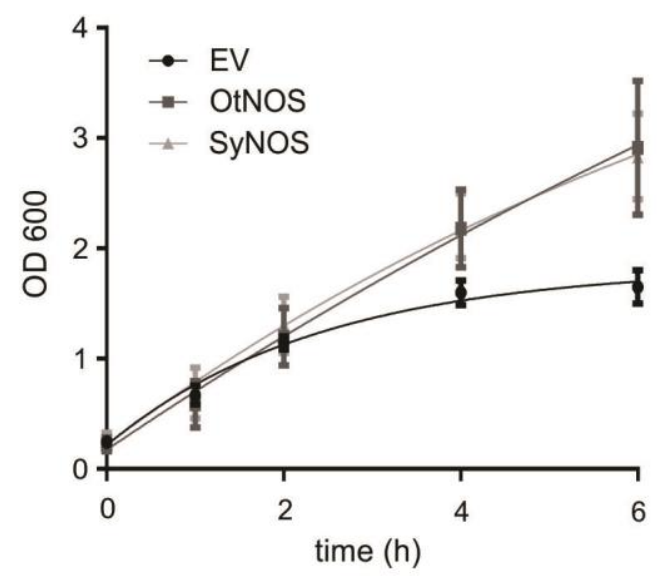

b
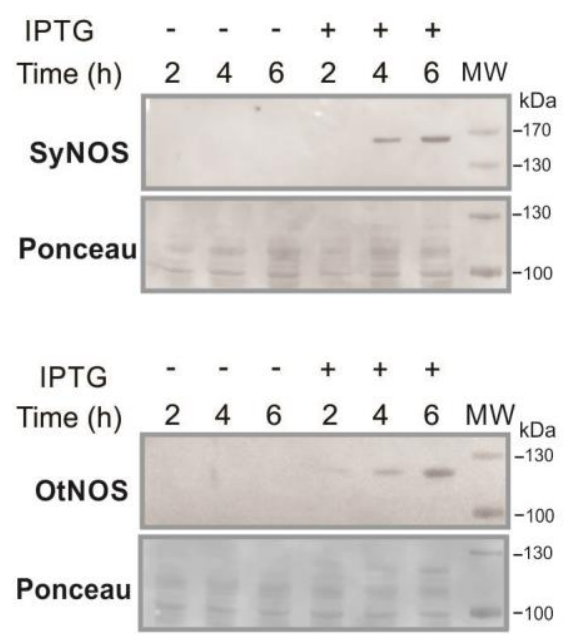

Fig. 1

Figure 1. Growth curves of $E$. coli cultures that express OtNOS or SyNOS. a E. coli cultures transformed with the vector pET24a (EV), pET24a-OtNOS (OtNOS) or pET24a-SyNOS (SyNOS), growing in LB medium, were induced with $0.1 \mathrm{mM}$ IPTG at $\mathrm{OD}=0.25$. Growth was followed during different time points at OD 600. b Western blot showing the presence of OtNOS and SyNOS at the different time points with and without the addition of $0.1 \mathrm{mM} \mathrm{IPTG}$. Full length blots are shown in Supplemental Fig. S3. 


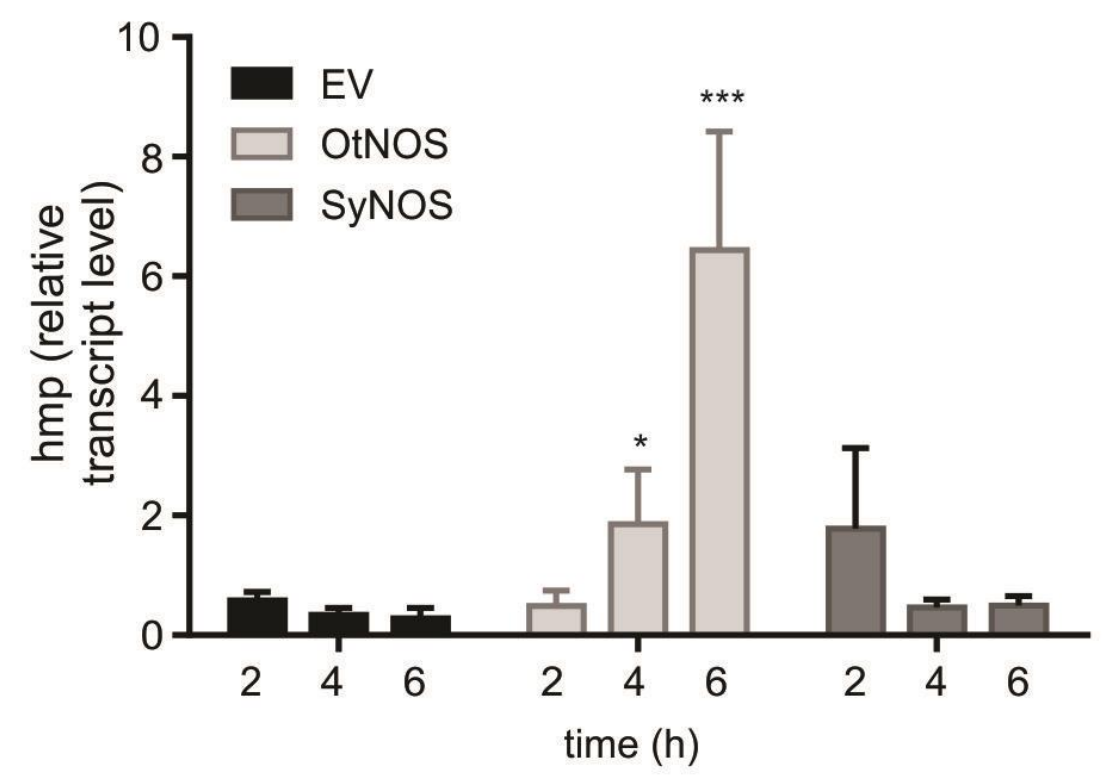

\section{Fig. 2}

Figure 2. Expression of NO dioxygenase $(\mathrm{hmp})$ in E. coli transformed with OtNOS or SyNOS. E. coli cultures (EV, OtNOS, SyNOS) were induced at OD $=0.25$ with $0.1 \mathrm{mM}$ IPTG. At the indicated time points, RNA was extracted, and cDNA synthesized. Expression of $h m p$ was analyzed by qPCR. The expression of hCat transcript was used as housekeeping to relativize hmp levels. Values are means and SE of two independent experiments with one and two biological replicates $(n=3)$. Asterisks means statistical difference respect to EV at the same time point (ANOVA, post hoc Dunnett method, ${ }^{*} p<$ $0.1 ; * * *<0.001)$. 
a

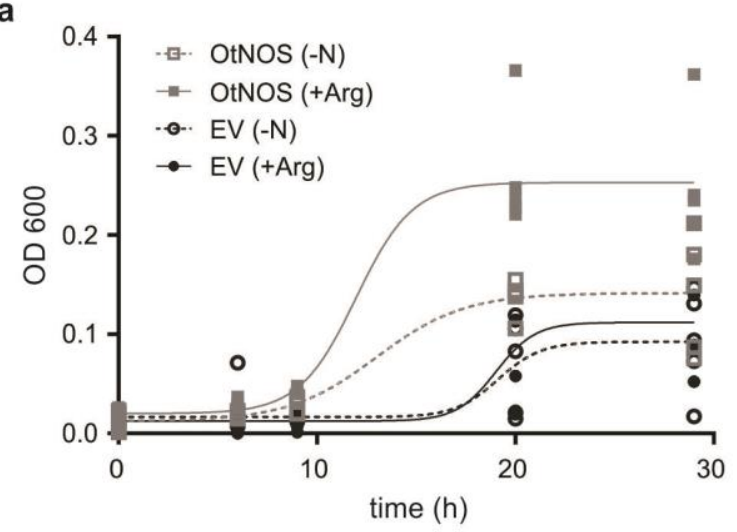

b

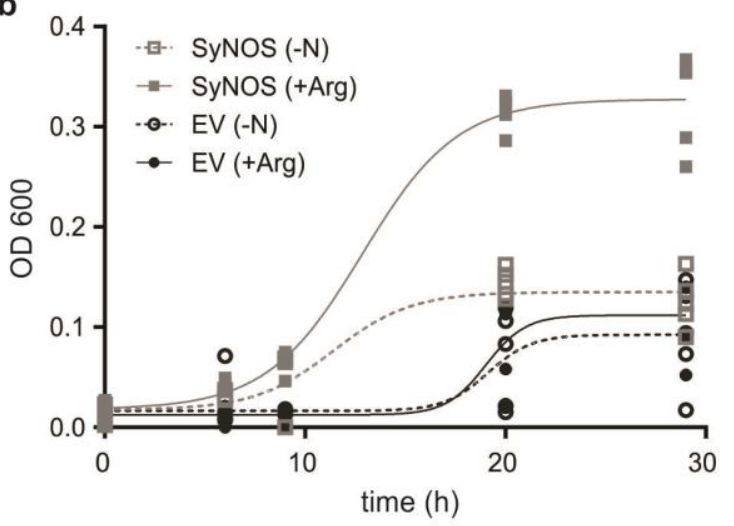

Fig. 3

Figure 3. E. coli cultures that express OtNOS or SyNOS growing in minimal medium (MM) with or without arginine as a sole N source. E. coli EV, (a) OtNOS and (b) SyNOS cultures were induced with $0.1 \mathrm{mM}$ IPTG for $1.5 \mathrm{~h}$. Cultures were diluted 1/100 in MM containing $0.2 \%(\mathrm{w} / \mathrm{v})$ glucose without nitrogen source (-N) or with $0.2 \%(\mathrm{w} / \mathrm{v})$ arginine (+Arg), $0.1 \mathrm{mM} \mathrm{IPTG}$ and $50 \mu \mathrm{g} / \mathrm{ml}$ Kan. Growth was followed measuring OD 600 at different time points $(n=5)$. 


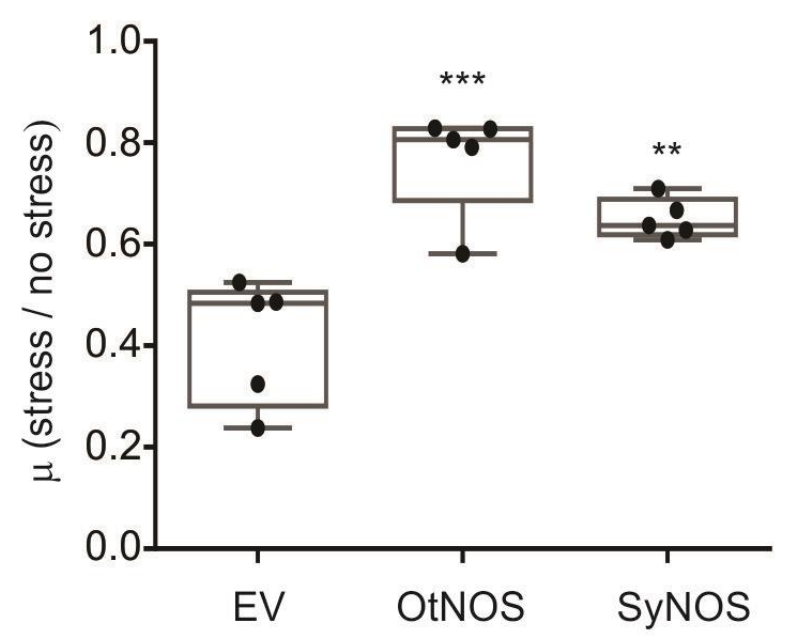

Fig. 4

Figure 4. E. coli cultures expressing OtNOS and SyNOS are protected from nitrosative stress. E. coli cultures were induced for $1.5 \mathrm{~h}$ with IPTG $0.1 \mathrm{mM}$. Cultures were diluted in LB medium to OD $600=$ 0.2. Nitrosative stress was triggered by addition of $1 \mathrm{mM}$ sodium nitroprusside (SNP). Growth was measured by following OD 600 for $3 \mathrm{~h}$. Data are expressed as the ratio of growth rate $(\mu)$ in the stress condition over non stress condition. Box plot from two independent experiments with two and three biological replicates $(n=5)$. Asterisks indicate statistical differences compared to EV (ANOVA, post hoc Dunnett method, $\left.{ }^{* *} \mathrm{p}<0.01,{ }^{* * *} \mathrm{p}<0.001\right)$. Representative growth curves of $E$. coli EV, OtNOS or SyNOS cultures subjected to nitrosative stress by SNP are shown in Supplemental Fig. S5. 
a

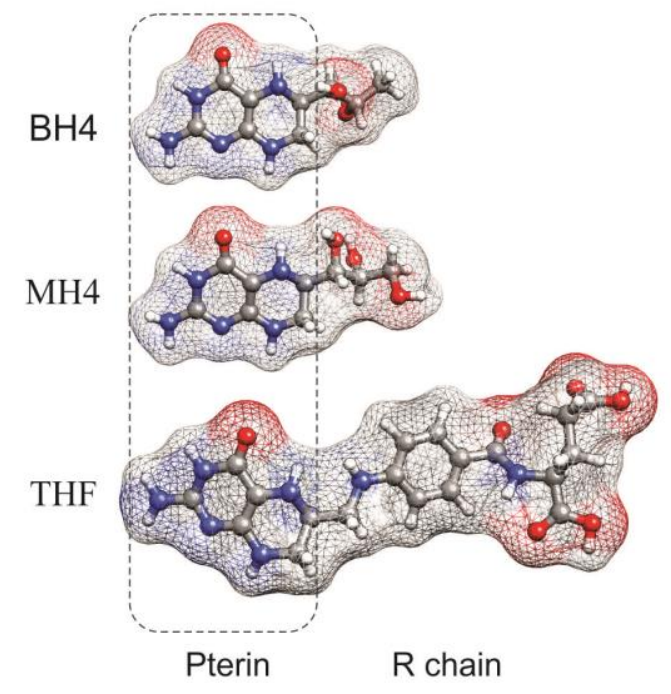

e

\begin{tabular}{ccc}
\hline & $\begin{array}{c}\mathrm{BH} 4 \\
\Delta \mathrm{G}^{\circ} \text { binding } \\
(\text { Kcal/mol })\end{array}$ & $\begin{array}{c}\mathrm{MH} 4 \\
\Delta \mathrm{G}^{\circ} \text { binding } \\
(\mathrm{Kcal} / \mathrm{mol})\end{array}$ \\
\hline iNOS & $-5,5^{*}$ & $-5,4$ \\
OtNOS & $-5,6$ & $-5,8$ \\
SyNOS & $-4,0$ & $-3,6$ \\
\hline
\end{tabular}

b

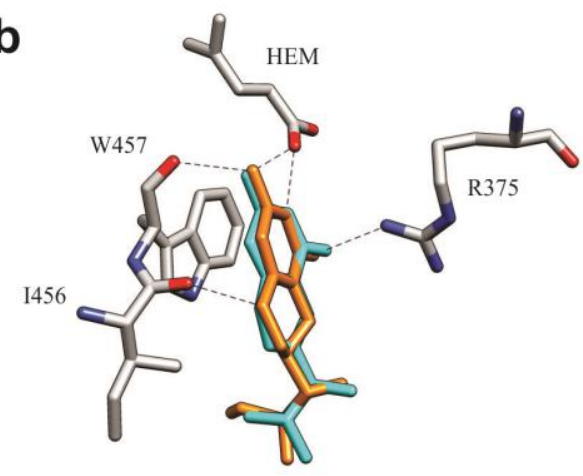

C

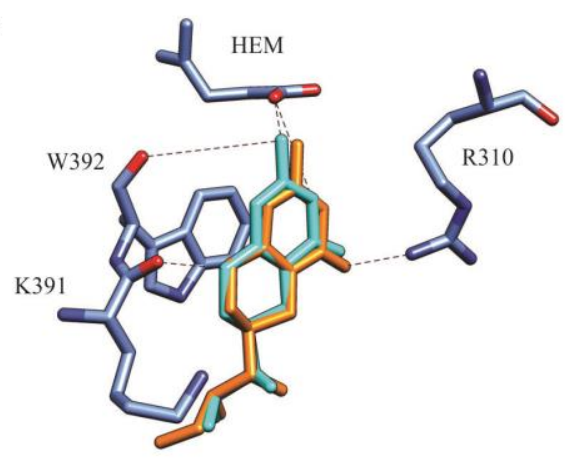

d

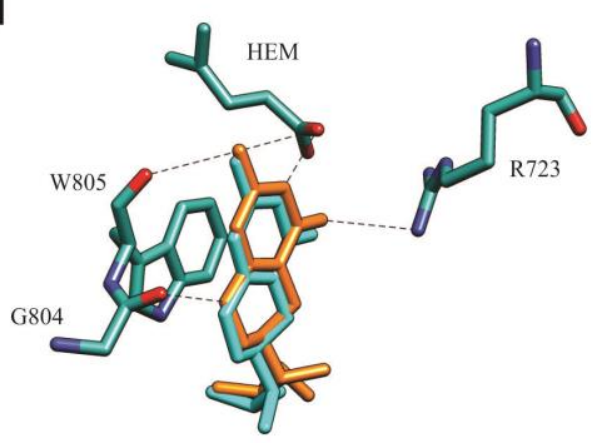

Fig. 5

Figure 5. 3D structures of the pterin binding residues showing $\mathrm{H}$-bonds network in NOS enzymes. a Ligand structures in a ball and stick representation showing its electrostatic surface. Positive and negative charges are in blue and red, respectively. Positions of $\mathrm{BH} 4$ (cyan) and $\mathrm{MH} 4$ (orange) by molecular docking are shown in (b) iNOS 3D structure (PDB file 1M8D), (c) OtNOS and (d) SyNOS. e Ligand binding energy obtained after docking using AutoDock Vina software. Asterisk indicates energy obtained after self-docking. 